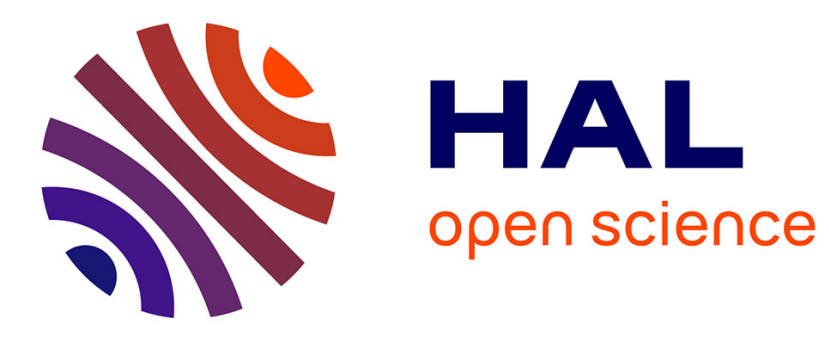

\title{
Numerical and experimental analysis of the vibroacoustic behavior of an electric window-lift gear motor
}

Emmanuel Rigaud, Pierre-Henri Cornuault, Benoît Bazin, Emmanuel

Grandais-Menant

\section{To cite this version:}

Emmanuel Rigaud, Pierre-Henri Cornuault, Benoît Bazin, Emmanuel Grandais-Menant. Numerical and experimental analysis of the vibroacoustic behavior of an electric window-lift gear motor. Archive of Applied Mechanics, 2018, 88 (8), pp.1395-1410. 10.1007/s00419-018-1378-6 . hal-02068264

\section{HAL Id: hal-02068264 \\ https://hal.science/hal-02068264}

Submitted on 15 Mar 2019

HAL is a multi-disciplinary open access archive for the deposit and dissemination of scientific research documents, whether they are published or not. The documents may come from teaching and research institutions in France or abroad, or from public or private research centers.
L'archive ouverte pluridisciplinaire HAL, est destinée au dépôt et à la diffusion de documents scientifiques de niveau recherche, publiés ou non, émanant des établissements d'enseignement et de recherche français ou étrangers, des laboratoires publics ou privés. 


\title{
Numerical and experimental analysis of the vibroacoustic behavior of an electric window-lift gear motor
}

\author{
Emmanuel Rigaud $^{1}$, Pierre-Henri Cornuault ${ }^{2}$, Benoît Bazin ${ }^{3}$, Emmanuel Grandais-Menant $^{3}$ \\ 1. Laboratoire de Tribologie et Dynamique des Systèmes, UMR CNRS 5513, Ecole Centrale de Lyon, \\ Université de Lyon, 36 avenue Guy de Collongue, 69134 ECULLY cedex, France \\ 2. Institut Femto-ST, UMR CNRS 6174, Département de Mécanique Appliquée, UBFC, 24 rue de
}

l'Epitaphe. 25000 BESANÇON, France

3. INTEVA Products, 14220 ESSON, France

Corresponding author: emmanuel.rigaud@ec-lyon.fr

\begin{abstract}
This paper focuses on the numerical analysis of the vibroacoustic behavior of an electric window-lift gear motor for automotive vehicle which consists of a DC motor and a worm gear. A dynamic modelling of the gear motor is proposed. The excitation sources correspond to radial electromagnetic forces applied to steel stator, electromagnetic input torque fluctuation, rotor mechanical imbalance, worm gear static transmission error and mesh stiffness fluctuations and gear wheel eccentricity. Parametric equations of motion are solved using an iterative spectral method. It allows the computing of the vibroacoustic response of the system, taking account of the interaction between the mesh stiffness fluctuation and the other excitations. The simulation results are validated from comparison with experimental vibroacoustic measurements performed with a specific test bench. Spectrograms of the dynamic response show components corresponding to the harmonics of the excitation spectra, as well as lateral components arising around the mesh frequency and the input torque fluctuation frequency. This spectral enrichment is generated by the interaction between the mesh stiffness fluctuation and the other excitations. The lateral components contribute little to the overall level of the vibroacoustic response but they may have a significant impact on the quality of noise radiated directly by the gear motor or indirectly by its supporting structure. Finally, the weights of the different excitation sources to the spatial-average mean-
\end{abstract}


square velocity of the radiating surface and the equivalent global dynamic force transmitted to the supporting structure are compared.

Keywords: electromagnetic force; mechanical imbalance; static transmission error; mesh stiffness fluctuation; eccentricity; dynamic transmitted force.

\section{Introduction}

Like other performances offered by an automotive vehicle such as safety, dynamics and fuel economy, the acoustic comfort within the passenger compartment has to be considered closely in the design process. During last decades, efforts have been continuously made to significantly reduce noise emission of powertrain [1]. Consequently, nuisance coming from the vehicle motorized accessories have now a significant impact on the noise perceived inside the automotive interior [2]. Among these, a gear motor equips each door of newer automotive vehicles in order to allow driver to go up and down the window. The window-lift gear motor is one of these peripheral organs which may annoy and disturb the driver when it is often used at vehicle stop [3].

The window-lift gear motor studied herein consists of a DC motor and a worm gear (cf. Figure 1). Its housing is made of a steel stator which supports diametrically opposed ferrites generating a permanent magnetic field, and a plastic part which supports the cage supporting two metal-graphitic brushes supplying electrical power to the rotor. The housing is attached to the door of the automotive vehicle at three fixation points. The rotor is guided by a front, a center and a rear journal bearings. It consists of a shaft on which coils are wound (number of coils: $N=10$ ) and connected to the $N$ blades of a rotating commutator. When the current flows in the coils positioned within the magnetic field, tangential (Lorentz) and radial (Maxwell) electromagnetic forces are created. The tangential forces generate the input torque allowing the rotating motion of the rotor. A worm is machined in the steel rotor, between the front and the center journal bearings. It is designed such as the mesh frequency $f_{m}$ is equal to the rotor frequency $f_{r}$. It meshes with a polyoxymethylene (POM) helical gear wheel in order to reduce the rotation velocity and increase the output torque (number of gear teeth: $Z=73$, worm gear ratio 1:73). The axial component of the mesh force is taken up by two curved pads acting as axial stops and mounted 
at each of the rotor ends. Finally, the gear wheel goes up and down the window depending on the direction of rotation of the window-lift motor, via a mechanical clutch connected to a drum and cables mechanism. Under standard operating conditions, the motor operates in open loop mode. A constant voltage is applied $(14.5 \mathrm{~V})$. The rotor velocity first increases briefly until reaching almost $6500 \mathrm{rpm}$, then remains constant during approximately 4 seconds, and then decreases in a short time when the voltage is removed. The output torque is nearly equal to 3 N.m.

Under operating conditions, various mechanical and electromagnetic phenomena generate excitation of the window-lift gear motor. They induce vibration and noise radiated by the gear motor housing itself, as well as dynamical forces transmitted to the door which can also radiate inside the automotive interior. The following excitation sources have been identified:

- The sliding contacts between worm and gear surfaces and between rotor/stator surfaces at the three journal bearings and the two axial pads generate broadband friction noise [4].

- At contacts between brushes and rotating commutator, (1) the sliding contact between surfaces of the brushes and the commutator also generates broadband friction noise, (2) some mechanical shocks occur when brushes come into contact with the commutator blades edges, and (3) commutation arcs occur when brushes lose contact with the blades [5]. The fundamental frequency characterizing the mechanical shocks and the commutation arcs is the harmonic H10.

- The fluctuation of the input electrical current at the contact between commutator and brushes and the periodic motion of the rotating coils through the permanent magnetic field generate periodic fluctuation of radial and tangential electromagnetic forces. Radial forces directly excite the steel housing of the stator [6]. Tangential forces and corresponding input torque are transmitted to the stator through the worm gear helical contact, the journal bearings and the axial pads. The fundamental frequency characterizing the periodic fluctuation of tangential and radial forces is the harmonic H10.

- Shaft misalignment and mechanical imbalance induced by the asymmetry of the rotor are responsible for radial forces transmitted to the stator through the journal bearings and the axial pads $[7,8]$. The 
fundamental frequency characterizing the periodic fluctuation of tangential and radial forces is the harmonic H1.

- The meshing between the worm and the gear wheel is the source of an internal excitation corresponding to the static transmission error (STE) fluctuation. STE corresponds to the difference between the actual position of the driven gear and its theoretical one [9]. Its characteristics depend on the instantaneous locations of the meshing tooth pairs resulting from tooth deflections and manufacturing errors. Furthermore, the gear mesh stiffness fluctuation associated with STE generates a parametric excitation of the mechanical system [10]. Under operating conditions, the internal excitation due to the meshing process is the origin of dynamic gear loads which are transmitted to the stator via the gear wheel body, the rotor, the journal bearings and the axial pads [10]. The fundamental frequency characterizing the worm gear mesh internal excitation is the harmonic H1.

- Manufacturing and mounting errors of the gear wheel are responsible for an eccentricity defect. This generates an additional component to the static transmission error STE(t) at a frequency corresponding to the rotation frequency of the wheel (H1/73).

The contribution of some excitations sources to the vibroacoustic behavior of the gear motor has been previously studied. From experiments performed with several window-lift gear motors, Diop [11] showed that the weight of the tonal, compared with the broadband noise, is more than $80 \%$ of the dynamic response in the frequency range $[0-6 \mathrm{kHz}]$. Furthermore, in the same article, the weight of the sources taking place at the brushes/commutator interfaces (friction noise, mechanical shocks, commutation arcs) has been studied using a specific test bench which allowed the remove of them one after the other. Dupont [12] proposed a simulation methodology to calculate the noise of an electrical motor generated by the radial (Maxwell) electromagnetic forces applied to the stator. First, time and space evolution of the radial magnetic forces is estimated using a 2D finite element model and an electromagnetic field simulation software. Then, the excitation is projected onto the 3D stator structural finite element model in order to calculate its dynamic response. Hamzaoui et al. [13, 14] proposed to describe the vibraocoustic response of a rotor on bearings system taking account of several defects such as misalignment and mechanical imbalance. For this, a set of equivalent point sources is defined and 
placed on the structure surface to estimate the radiated noise. Concerning excitation sources generated by the meshing process, Tavakoli et al. [15] and Rigaud et al. [16] proposed a modelling of the gear teeth contact allowing evaluation of static transmission error and mesh stiffness periodic fluctuations. The methodology was then extended to the worm gear mesh $[17,18]$. Prediction of the whining noise induced by these excitations was performed by Rigaud [10] and Carbonelli [19] from solving the parametric equations of motion describing the system dynamic response. Models of the overall dynamic response should also consider potential coupling between the different excitation sources. For this purpose, Dupont et al. [12] analyzed effect of static and dynamic rotor eccentricity on the radial magnetic excitation and the noise radiated by an automotive electric motor. Taking account of the dynamic eccentricity generated by misalignment leads to an enrichment of the excitation by additional components that combine the initial electromagnetic frequencies and the rotation frequency of the rotor.

This article presents a numerical approach for differentiating and prioritizing the main excitation sources of the window-lift gear motor that are modelled beforehand, in particular the fluctuations of the radial (Maxwell) electromagnetic forces, the electromagnetic input torque applied to the rotor, the static transmission error and the mesh stiffness associated with the worm gear system, as well as the rotor mechanical imbalance and the gear wheel eccentricity.

The first part describes the modelling of the different excitation sources. The second part describes the parametric equation of motion with periodic coefficients, the finite element modelling of the electric window-lift gear motor performed to compute its modal basis and the computing of its dynamic response using an iterative spectral method. The simulation results are compared with experimental ones obtained from a test bench designed and built in order to analyses the vibroacoustic response of the window-lift gear motor. They are analyzed to identify the frequency content and the amplitude of the dynamic response, and compared in order to assess the relative weight of the studied excitation sources and their contribution to the vibroacoustic behavior of the gear motor. 


\section{Modelling of the excitation sources}

\subsection{Electromagnetic forces}

The fluctuations of the electromagnetic forces are computed using the electromagnetic field simulation software Maxwell ${ }^{\circ}$. A 2D finite element modelling of the coils and their armature, the ferrites and the air gap is performed in order to evaluate the electromagnetic field in steady state operating condition under the following assumptions. The 10 coils have the same resistance and show no asymmetry. The rotor motion is perfectly centered with respect to the magnetic field generated by the ferrites. There is no iron loss (due to the hysteresis of the ferromagnetic material) and no friction. The line resistance is equal to $0.15 \Omega$ and the applied voltage is equal to $14.5 \mathrm{~V}$.

The numerical simulation performed allows computation of the spatial distribution of the radial and tangential magnetic fields $B_{R}(t)$ and $B_{T}(t)$ in the air gap (between 0 and $360^{\circ}$ ), for different successive rotor positions describing $1 / 10^{\text {th }}$ of a rotation (see Figure 2 ). The magnetic fields have two major corrugations related to the angular position of the two ferrites and ten minor corrugations associated with the instantaneous angular position of the coils. The maximum flux is obtained when the coils median plane coincides with the ferrite median plane. The instantaneous normal and tangential stresses $\sigma_{n}(t)$ and $\sigma_{t}(t)$ of the Maxwell tensor (Maxwell and Lorentz pressures), corresponding to the surface densities of the radial and tangential forces are then estimated from the preceding magnetic fields $B_{R}(t)$ and $B_{T}(t)$ :

$$
\begin{gathered}
\sigma_{n}(t)=\frac{B_{R}(t)^{2}-B_{T}(t)^{2}}{2 \mu_{0}} \\
\sigma_{t}(t)=\frac{B_{R}(t) B_{T}(t)}{\mu_{0}}
\end{gathered}
$$

with $\mu_{0}$ the vacuum permeability $\left(4 \pi \cdot 10^{-7} \mathrm{~m} \cdot \mathrm{kg} \cdot \mathrm{s}^{-2} \cdot \mathrm{A}^{-2}\right)$.

On the one hand, time and space evolution of the radial electromagnetic forces is projected onto the 3D steel stator structural finite element model according to a procedure similar to the one proposed by Dupont [12]. For each angular position of the air gap, the Fourier transform of the time evolution of the 
surface density of the radial forces allows computation of the complex spectrum of the normal forces applied on the steel stator of the gear motor. The first three components are retained, corresponding to the harmonics $\mathrm{H} 10, \mathrm{H} 20$, and $\mathrm{H} 30$ of the rotor frequency. For each harmonic, the normal forces are then applied to the nodes of the model finite elements corresponding to the radial surface of the stator using a procedure which transpose the results from the electromagnetic mesh of the air gap (2D) on the corresponding nodes of the mesh finite elements of the stator (3D). The force distribution is assumed to be uniform over the length of the coils.

On the other hand, the tangential electromagnetic forces generate the input torque $T(t)$ evaluated from the following equation:

$$
T(t)=R \int \sigma_{t}(t) d S
$$

with $R$ the coils radius.

Figure 3 displays the time evolution and amplitude spectrum of the input torque for the standard operating regime $(6500 \mathrm{rpm})$.

\subsection{Mechanical imbalance}

The imbalance of the rotor is measured at the output of the production line, once the coils and the rotating collector are mounted. The rotor is then rebalanced by removing material from machining a flattened surface on the armature of the coils. The angular position and the depth of the flat are calculated in order to limit the final amplitude of the imbalance to a value lower than the following value:

$$
m R<8.10^{-7} \mathrm{~kg} . \mathrm{m}
$$

The mechanical imbalance of the rotor is then modelled using a rotating force at the center of the coils whose frequency corresponds to harmonic $\mathrm{H} 1$ of the rotor frequency and amplitude is proportional to the square of the rotor velocity. The two radial components are described below:

$$
\begin{gathered}
F_{y}=m R \omega^{2} \cos (\omega t) \\
F_{z}=m R \omega^{2} \sin (\omega t)
\end{gathered}
$$




\subsection{Static transmission error STE(t) and mesh stiffness fluctuations $k(t)$ of the worm gear} system

The calculation of the static transmission error (STE) is well known. It is based on the resolution of the equation describing the static contact between the gear teeth (see for example Tavakoli et al. [15] and Rigaud et al. [16]). For a given load $F$ applied to the worm gear contact, static transmission error is calculated for a set of successive positions $\theta$ of the driving wheel, in order to evaluate its periodic time evolution. For each angular position $\theta$ of the driving wheel, a kinematic analysis of gear mesh allows the location of contact line for each loaded tooth pair. The contact line is discretized in order to introduce the compliance matrix $\mathbf{H}$ that links the displacements to the applied forces at the discrete points. In the particular case of worm gear used in the gear motor, the worm teeth machined in the steel rotor (Young modulus $=210 \mathrm{GPa}$ ) have much greater stiffness than the plastic wheel teeth (POM, Young modulus=1 GPa). Hence, only the compliance of the gear wheel is taken into account. It is calculated from a thick plate model using a Reissner-Mindlin theory [20] where the variable thickness $h(x)$ of the plate corresponds to the tooth thickness [21]. The Hertz deformation is also added in the compliance matrix $\mathbf{H}$. The vector $\mathbf{e}$ describes the initial distance from the gear surface to the pinion surface, induced by manufacturing errors and parallelism errors which result from elasto-static deformation of the gear motor. For each position $\theta$ over a meshing period, the resolution of the contact equations leads to the evaluation of STE $\delta(\theta)$ and load distribution $\mathbf{P}$ along the contact line. Contact equation can be written as follows:

$$
\left\{\begin{array}{c}
\mathbf{H} . \mathbf{P}=\delta(\theta) . \mathbf{1}-\mathbf{e} \\
{ }^{t} \mathbf{1} . \mathbf{P}=F
\end{array}\right.
$$

under the following constraints:

$$
\left\{\begin{array}{c}
\text { H. } \mathbf{P}+\delta(\theta) . \mathbf{1} \leq \mathbf{e} \\
P_{i} \geq 0
\end{array}\right.
$$

For each of the successive positions $\theta$ of the driving wheel, the mesh stiffness $k(\theta)$ is defined as the derivative of the transmitted load $F$ relative to STE: 


$$
k(\theta)=\frac{\partial F}{\partial \delta(\theta)}
$$

The mesh stiffness is evaluated for the set of successive positions $\theta$ of the driving wheel, in order to evaluate its periodic time evolution. Figure 4 displays the time evolution and amplitude spectrum of the static transmission error and mesh stiffness fluctuation generated by the meshing process. The first five components are retained, corresponding to the harmonics $\mathrm{H} 1$ to $\mathrm{H} 5$ of the rotor frequency.

\subsection{Gear wheel eccentricity}

Eccentricity is modelled using an additional component to the static transmission error spectrum. The corresponding frequency is the wheel rotation frequency (H1/73 because of the worm gear ratio), and the amplitude $(40 \mu \mathrm{m})$ is derived from the manufacturing and assembly tolerances.

\section{Computing of the gear motor dynamic response}

The dynamic response of a gear system is usually described in the frequency modal domain. The solution is projected onto the modal basis determined from the average mass and stiffness characteristics of the system. The first subsection of this paragraph presents the parametric equation of motion of the discretized gear system. The second subsection presents structural finite element modelling of the electric window-lift gear motor performed in order to obtain its modal basis. The third subsection presents the computing of its dynamic response using an iterative spectral method which takes account of the coupling phenomena between the mesh stiffness fluctuation and the other excitation sources of the kinematic chain. The last subsection presents indicators of particular interest, that is to say spatialaverage mean-square velocity of the gear motor housing and global dynamic force transmitted to the supporting structure.

\subsection{Parametric equation of motion}

For a stationary regime, the dynamic behavior of the discretized gear motor is described by a parametric equation of motion with periodic coefficients. It can be written in the following matrix form:

$$
\mathbf{M}_{\mathbf{F E}} \ddot{\mathbf{x}}(t)+\mathbf{C} \dot{\mathbf{x}}(t)+\mathbf{K}_{\mathbf{F E}} \mathbf{x}(t)+k(t) \mathbf{R} \mathbf{R}^{\mathbf{T}} \mathbf{x}(t)=k(t) \mathbf{R R}^{\mathbf{T}} \boldsymbol{x}_{\boldsymbol{s}}(t)+\boldsymbol{F}(t)
$$


$\mathbf{x}$ is a vector $(1 \mathrm{x} \mathrm{n})$ representing the generalized coordinates used to describe the motion of the system discretized in $\mathrm{n}$ degrees of freedom. $\mathbf{M}_{\mathbf{F E}}$ and $\mathbf{K}_{\mathbf{F E}}$ are the mass and stiffness matrices ( $\mathrm{n} \times \mathrm{n}$ ) provided by the finite element method, (without the elastic coupling between the worm and the gear wheel (see 3.2). $\mathbf{C}$ is a viscous damping matrix defined a posteriori through equivalent modal damping coefficients. In steady state operation, the mesh stiffness $k(t)$ is a periodic function of time. The corresponding parametric excitation is introduced by the term $k(t) \mathbf{R R}^{\mathbf{T}} \mathbf{x}(t)$ which couples the 12 degrees of freedom describing the dynamic responses of the worm and the driven wheel centers. Vector $\mathbf{R}(1 \times 12)$ is associated with the worm gear geometry. The term $k(t) \mathbf{R R}^{\mathbf{T}} \boldsymbol{x}_{\boldsymbol{s}}(t)$ represents the static transmission error excitation projected on the degrees of freedom of the worm and the driven wheel centers. The vector $\boldsymbol{F}(t)(1 \times \mathrm{n})$ is the generalized force vector associated with the other excitations.

The equation of motion can be projected onto the modal basis of the discretized gear motor as follows [22]:

$$
\mathbf{m} \ddot{\mathbf{q}}(t)+\mathbf{c} \dot{\mathbf{q}}(t)+\mathbf{k q}(t)+g(t) \mathbf{d q}(t)=\mathbf{s}(t)
$$

Assuming that the $\mathrm{p}$ first modes are retained, $\mathbf{m}, \mathbf{c}$ and $\mathbf{k}$ are the usual modal mass damping and stiffness diagonal matrices ( $\mathrm{p} \times \mathrm{p}), \mathbf{q}$ is the modal coordinates vector $(1 \times \mathrm{p}), g(t)$ is the centered mesh stiffness periodic fluctuation, $\mathbf{d}$ is a non-diagonal matrix ( $\mathrm{p}$ x p) introduced by the parametric excitation which couples up the equations of motion, $\mathbf{s}(t)$ is the modal generalized force vector $(1 \mathrm{xp})$.

\subsection{Finite element modelling of the electric window-lift gear motor}

The electric window-lift gear motor is modelled using the finite element method in order to compute its modal basis. The steel stator is discretized using shell elements with 4 nodes and 6 degrees of freedom per node. The plastic part of the housing, the ferrites, the bearings supports, the elastomeric seal and the cage supporting the brushes are discretized using 3D structural solid elements with 8 nodes and 3 degrees of freedom per node. The rotor is discretized using beam elements with 2 nodes and 6 degrees of freedom per node. The additional components (coils, collector) and the gear wheel are modelled by added mass and inertia elements. Finally, the model is about 60000 elements and 400000 degrees of freedom. The size of elements has been chosen mainly to describe the geometric complexity as well to ensure 
convergence of the solution. For each of the sub-assemblies (steel stator, plastic part and rotor), the results of modal analysis are not affected by changing the mesh refinement.

An experimental modal analysis under free-boundary conditions has been performed for the steel stator, the plastic part and the rotor, in order to adjust parameters of the structural finite element model such as the stator average thickness, the plastic part Young modulus and the masses and inertia added to the rotor. Differences between experimental and numerical first natural frequencies of the sub-assemblies are less than $2 \%$.

The elastic coupling between the rotor and the housing is modelled using radial stiffness elements for the three journal bearings (front, center and rear) and axial stiffness elements for the two axial stops (front and rear). The elastic coupling between the worm and the gear wheel is modelled using a $12 \times 12$ stiffness matrix which couples the 6 degrees of freedom of the node corresponding to the wheel center to the 6 degrees of freedom of the rotor node corresponding to the worm center [10]. This matrix is defined from the geometrical characteristics of the worm gear and the mean value of the mesh stiffness.

The modal analysis of the gear motor shows a low number of eigenvalues due to the compactness of the structure ( 80 modes in the frequency range $[0 ; 10 \mathrm{kHz}]$, in addition to the rigid body mode corresponding to the input/output law of the gear motor, that is to say rotation of the rotor and the gear wheel with a ratio 1:73). The main meshing mode frequency involving the mesh stiffness is about $4 \mathrm{kHz}$. In the operating range of the gear motor $(0-8000 \mathrm{rpm}$, i.e. $0-133 \mathrm{~Hz})$, amplification of the dynamic mesh force due to the resonant excitation of this mode by the mesh frequency and its first harmonics [23] never appends.

\subsection{Resolution of the equation of motion using the spectral iterative method}

The use of time discretization methods leads to prohibitive calculation times when a discretization over a long period is required for low frequency excitation and a fine time step is required for high frequency excitation. So that, parametric equation of motion is solved using the spectral and iterative method. The method is described in details in [22]. The main principles are the followings. The first one is to solve the coupled equations of motion in the spectral domain, keeping only the steady-state response of the 
system (assuming a sufficient damping to ensure asymptotic stability, the free response is a decreasing exponential). The second one is to condense the coupled equations on the worm and gear wheel degrees of freedom in order to explicit the dynamic transmission error. The third one is to compute the solution according to an iterative scheme. The Fourier transform of the modal coordinate vector is then deduced. Finally, the spectrum of the vibratory response (amplitude and phase) at any degree of freedom of the discretized system is obtained, going back to the physical basis. The spectral iterative method allows solving of large systems of periodic differential equations with minimal computation times.

\subsection{Spatial-average mean-square velocity of the gear motor and global dynamic force}

\section{transmitted to the supporting structure}

Among all the dynamic responses, the following indicators are of particular interest. First, the acoustic power radiated from the gear motor is:

$$
\Pi_{a c}=\rho_{0} c_{0} S \sigma_{\text {rad }}<\overline{V^{2}}>_{S}
$$

$\rho_{0}$ is the air density, $c_{0}$ is the velocity of sound in the air, $S$ is the radiating surface of the gear motor, $\sigma_{\text {rad }}(\omega)$ is the radiation factor. $\left\langle\overline{V^{2}}\right\rangle_{S}$ is the spatial-average mean-square velocity of the radiating surface. It is deduced from the component of the vibratory response $\dot{\mathbf{x}}(t)$ normal to the surface at each degree of freedom of the housing [24]:

$$
<\overline{V^{2}}>_{S}=\frac{1}{S} \int_{S} \overline{\dot{\mathbf{x}}^{2}(t)} d s
$$

Finally, the acoustic power radiated from the gear motor is estimated assuming a unit radiation factor from $\rho_{0} c_{0} S<\overline{V^{2}}>_{s}$.

Second, an equivalent global dynamic force $F_{t}$ transmitted to the supporting structure by the gear motor is introduced from the set of reaction forces $F_{x}, F_{y}$ and $F_{z}$ at the three fixation points as follows:

$$
F_{t}=\sum_{i=1}^{3} \sqrt{F_{x i}^{2}+F_{y i}^{2}+F_{z i}^{2}}
$$

It can be at the origin of the acoustic radiation of the vehicle door and therefore have a direct impact on the noise perceived inside the passenger compartment. 
The level (in $\mathrm{dB}$ ) of the spatial-average mean-square velocity $L_{S V^{2}}(d B)$ and the equivalent global dynamic transmitted force $L_{F t}(d B)$ are calculated as follows:

$$
\begin{gathered}
L_{S V^{2}}(d B)=10 \log \left(\frac{\rho_{0} c_{0} S<\overline{V^{2}}>_{S}}{\Pi_{\text {ref }}}\right) \\
L_{F t}(d B)=10 \log \left(\frac{F_{t}}{F_{\text {ref }}}\right)
\end{gathered}
$$

with reference values $F_{r e f}=1 N$ and $\Pi_{r e f}=10^{-12}$ Watts (reference value used to estimate the radiated sound power).

Figures 5 and 6 display the spectrograms of the spatial-average mean-square velocity $L_{S V^{2}}(d B)$ and the equivalent global dynamic transmitted force $L_{F t}(d B)$ for different operating regimes in the range [0 $8500 \mathrm{rpm}]$ and the associated amplitude spectrum of the dynamic responses (in physical units) for the standard operating regime $(6500 \mathrm{rpm})$.

The following excitations are considered:

- radial electromagnetic forces (Maxwell pressures) applied to the steel stator (a), (f),

- electromagnetic input torque fluctuation (b), (g),

- mechanical imbalance (c), (h),

- static transmission error (d), (i),

- gear wheel eccentricity (e), (j).

Figure 7 displays the evolution of the root mean square value of the dynamic responses versus operating regime.

\section{Experimental test bench and measurement protocol}

A test bench has been designed and built in order to measure the vibroacoustic response of the windowlift gear motor (cf. Figure 8). This one is mounted on a rigid and compact frame at the three points corresponding to its fixation points. An output shaft driven by the gear wheel is connected to a magnetic powder brake by a mechanical coupling. The load applied by powder brake is measured thanks to a torque meter. The kinematic chain is guided in rotation by rolling bearings. The output gear motor 
rotation speed is measured thanks to a speed meter fixed to the end of the output shaft. The window-lift gear motor is energized thanks to an electrical supply system. The test bench is controlled using a specific software. Tests are performed for an output torque equal to 3 N.m corresponding to the load usually required to translate the window and for different operating regimes. First, the input rotation speed linearly increases from 0 to $6500 \mathrm{rpm}$. Test duration is $60 \mathrm{~s}$. Then, the standard stationary regime $(6500 \mathrm{rpm})$ is maintained during $10 \mathrm{~s}$. The vibroacoustic response of the window-lift gear motor is characterized using the following instrumentation. The vibratory response is measured thanks to a piezoelectric accelerometer glued on the outer face of the plastic housing close to the brushes/commutator contacts. It has been previously demonstrated that this accelerometer location allows for acquiring a signal level representative of the overall gear motor vibroacoustic response [11]. Complementary vibratory responses can be performed thanks to a laser vibrometer. Sound pressure is measured thanks to a $1 / 4$ in microphone placed at $70 \mathrm{~mm}$ of the gear motor. The normal and transversal forces at the fixation points are measured thanks to two monoaxial and one triaxial piezoelectric force transducers. Time evolutions of signals are recorded using a multi channels acquisition card and post processed. The sampling frequency is $44.1 \mathrm{kHz}$. Figure 9 displays the amplitude spectrum of the reference acceleration during the standard operating regime $(6500 \mathrm{rpm})$ (Figure 9a) and the spectrogram during the increasing sweep (Figure 9b).

\section{Results and discussion}

The spectrograms of the numerical dynamic response show components corresponding to the harmonics of the excitation spectra considered: H1/73 for the gear wheel eccentricity, $\mathrm{H} 1$ for the mechanical imbalance, $\mathrm{H} 1, \mathrm{H} 2, \mathrm{H} 3$, etc. for the static transmission error, $\mathrm{H} 10, \mathrm{H} 20, \mathrm{H} 30$ for the electromagnetic radial forces and input torque fluctuation. The parametric equation of motion leads to a coupling of the mesh stiffness fluctuation with the other excitation sources. The coupling with the gear wheel eccentricity generates a frequency enrichment of the dynamic response which results in the presence of lateral components around harmonics of the mesh frequency $(\mathrm{H} 1 \pm 1 / 73, \mathrm{H} 2 \pm 1 / 73, \ldots, \mathrm{H} 5 \pm 1 / 73)$. The coupling with mechanical imbalance and mesh stiffness is negligible and does not generate any 
significant new component. The coupling with the static transmission error results in a modification in the amplitude of the components multiple of the mesh frequency (H1, H2, etc.). Finally, the coupling with the electromagnetic input torque generates a frequency enrichment of the dynamic response, which results in the presence of numerous lateral components (H10 $\pm 1, \mathrm{H} 10 \pm 2$, etc., $\mathrm{H} 20 \pm 1, \mathrm{H} 20 \pm 2$, etc.). The amplitude of the lateral components arising from the coupling with the mesh stiffness fluctuation is generally less than that of the main components. They are thus not very involved in the overall amplitude of the vibroacoustic response. Nevertheless, they are at the origin of modulation phenomena which noticeably modify the sound quality of the noise radiated directly by the gear motor or indirectly by the supporting structure to which the forces are transmitted at the fixation points. Consequently, they may have a significant impact on the user feelings.

Some amplification peaks of the dynamic response are observed. They correspond to the resonant excitation of some natural modes of the gear motor. For example, considering the electromagnetic radial forces, harmonic $\mathrm{H} 10$ leads to a resonant excitation of the third mode $(640 \mathrm{~Hz}$, modal shape corresponding to a twist deformation of the plastic part of the housing) at $3860 \mathrm{rpm}$. No significant amplification peaks were observed in the range of standard stationary operating speeds (6000$8000 \mathrm{rpm})$. On the other hand, considering mechanical imbalance, harmonic H1 leads to a resonant excitation of the first mode ( $95 \mathrm{~Hz}$, modal shape deformation mainly localized at the steel stator) at $5800 \mathrm{rpm}$, that is in the vicinity of the standard stationary operating regime of the gear motor.

Figure $7 \mathrm{a}$ allows the comparison between the spatial-average mean-square velocity $\left\langle\overline{V^{2}}\right\rangle_{s}$ induced by the different excitation sources considered. $\left\langle\overline{V^{2}}\right\rangle_{S}$ is mainly generated by the electromagnetic radial forces between 0 and $4500 \mathrm{rpm}$ and then by the rotor mechanical imbalance above $4500 \mathrm{rpm}$, corresponding to the standard operating regimes range. The level generated by the static transmission error is of a secondary order. The ones generated by the input torque fluctuation and by the gear wheel eccentricity fault are much lower than the other contributions throughout the operating regime range, despite the spectral enrichment generated by the coupling with the mesh stiffness fluctuation $(-30 \mathrm{~dB}$ compared to that generated by the electromagnetic radial forces and mechanical imbalance). Assuming a unit radiation factor, $\left\langle\overline{V^{2}}\right\rangle_{S}$ corresponds to a maximum radiated sound power level equal to $74 \mathrm{~dB}$ 
at $5800 \mathrm{rpm}$. The level observed at the steel stator surface is greater than that observed at the plastic part of the housing, whether it is generated by electromagnetic radial forces or by the mechanical imbalance. This result is confirmed by experimental measurements. $\left\langle\overline{V^{2}}\right\rangle_{s}$ reaches $1(\mathrm{~mm} / \mathrm{s})^{2}$ for the regime corresponding to a resonant excitation of the first mode $(95 \mathrm{~Hz})$ by the mechanical imbalance, which is also in good agreement with the experimental measurements [25].

It is observed that the response generated by imbalance is located at low frequency $(\mathrm{H} 1,0-133 \mathrm{~Hz})$, whereas that generated by the static transmission error $(\mathrm{H} 1-\mathrm{H} 5,0-666 \mathrm{~Hz})$ and by the electromagnetic radial forces $(\mathrm{H} 10, \mathrm{H} 20, \mathrm{H} 30,0-4000 \mathrm{~Hz})$ are located at higher frequencies. An A-weighting similar to that used in acoustics (IEC 61672-1 standard) is introduced to take account of the auditory sensitivity of the observer for each frequency band. Conclusions obtained are different (see figure 7b): the spatialaverage mean-square velocity and consequently the radiated sound power are mainly generated by the electromagnetic radial forces between 0 and $5500 \mathrm{rpm}$. Assuming a unit radiation factor, the corresponding maximum radiated sound power level is equal to $63 \mathrm{dBA}$ at $3800 \mathrm{rpm}$. Beyond $5500 \mathrm{rpm}$, the weights of electromagnetic radial forces, rotor mechanical imbalance and worm gear static transmission error are of the same order of magnitude. The effective value for the overall spatial-average mean-square velocity corresponds to a radiated sound power level ranging between $53 \mathrm{dBA}$ and $56 \mathrm{dBA}$, which is in good agreement with the experimental measurements [25].

Figure $7 \mathrm{c}$ allows the comparison between the equivalent global dynamic forces $F_{t}$ transmitted to the supporting structure and induced by the different excitation sources considered. In the absence of gear wheel eccentricity fault, $F_{t}$ is generated mainly by the static transmission error between 0 and $3000 \mathrm{rpm}$. It is generated mainly by electromagnetic normal forces between 3500 and $4500 \mathrm{rpm}$. It is mainly generated by the rotor mechanical imbalance around $5800 \mathrm{rpm}$, due to the resonant excitation of the first mode $(95 \mathrm{~Hz})$. In the vicinity of the standard stationary operating regime range $(6000-8000 \mathrm{rpm})$, the weights of electromagnetic radial forces, rotor mechanical imbalance and worm gear static transmission error are of the same order of magnitude. The contribution of the engine torque fluctuation is much lower than the other contributions throughout the operating regimes range. The effective value for the overall equivalent global dynamic force is $F_{t}=5 \mathrm{~N}\left(L_{F t}=5.3 \mathrm{~dB}\right)$. Simulations performed show that 
the normal forces and the tangential forces are of the same order of magnitude. These results are in good agreement with the experimental measurements when the gear wheel rotation frequency is filtered. Taking into account the gear wheel eccentricity generates an added contribution to $F_{t}$ at very low frequency (H1/73). Its effective value is $F_{t}=9.3 N\left(L_{F t}=9.7 \mathrm{~dB}\right)$. This result is also in good agreement with the experimental measurements [25].

\section{Conclusion}

In this study, a numerical analysis was performed in order to predict the vibroacoustic response of an electric window-lift gear motor due to excitation sources such as electromagnetic radial forces and input torque fluctuation, rotor mechanical imbalance, worm gear static transmission error and stiffness fluctuation and gear wheel eccentricity. A structural finite element model of the gear motor was built and model parameters were adjusted in order to make similar numerical and experimental modal analysis. An iterative spectral method has been used to solve the parametric equations of motion and to calculate the vibroacoustic response of the system taking account of the coupling phenomena between the mesh stiffness fluctuation and the other excitation sources of the kinematic chain.

The spectrograms of the dynamic response show components corresponding to the harmonics of the excitation spectra considered: H1/73 for the gear wheel eccentricity, $\mathrm{H} 1$ for the mechanical imbalance, $\mathrm{H} 1, \mathrm{H} 2, \mathrm{H} 3$, etc. for the static transmission error, $\mathrm{H} 10, \mathrm{H} 20, \mathrm{H} 30$ for the electromagnetic radial forces and input torque fluctuation. The coupling of mesh stiffness with other excitation sources results in a modification of the mesh frequency harmonics amplitude and generates a frequency enrichment of the dynamic response characterized by lateral components around harmonics of the mesh frequency and around harmonics associated with the input torque fluctuation. The lateral components contribute little to the overall level of the vibroacoustic response but they may have a significant impact on its nature and the quality of the noise radiated directly by the gear motor or indirectly by the supporting structure to which the forces are transmitted at the fixation points.

Finally, torque fluctuations and the gear wheel eccentricity are secondary sources to the vibroacoustic radiation of the gear motor. When an A-weighting is used, the spatial-average mean-square velocity of 
the gear motor radiating surface is mainly generated by electromagnetic radial forces applied to the steel stator between 0 and $5500 \mathrm{rpm}$. Assuming a unit radiation factor, it corresponds to a maximum radiated sound power level of $63 \mathrm{dBA}$. Beyond $5500 \mathrm{rpm}$, the weight of the electromagnetic radial forces, the rotor mechanical imbalance and the worm gear static transmission error is of the same order of magnitude. The effective value for the spatial-average mean-square velocity corresponds to a radiated sound power level of the order of $55 \mathrm{~dB}$ in good agreement with the experimental measurements.

On the other hand, for the standard stationary operating regime range of the gear motor $(6000-8000$ $\mathrm{rpm}$ ), the gear wheel eccentricity generates a high amplitude force transmitted to the supporting structure at very low frequency, which adds to the transmitted force generated in an equivalent manner by electromagnetic radial forces, mechanical imbalance and static transmission error. A collaborative work with car manufacturers would make possible to calculate the transmitted forces not by considering the embedded fixation points but taking into account the mechanical impedance of the supporting structure. Furthermore, the predictive calculation of the vibroacoustic behavior of the door could be useful to evaluate the overall noise generated in the passenger compartment by the gear motor.

\section{Acknowledgement}

The authors thank Inteva Products Company for financial and technical supports. The authors also thank the LabCom LADAGE (LAboratoire de Dynamique des engrenAGEs), created by the LTDS and the Vibratec Company and sponsored by the "Agence Nationale de la Recherche" in the program ANR-14LAB6-0003.

\section{References}

[1] Qatu M., Abdelhamid M., Pang J., Sheng G., 2009, "Overview of automotive noise and vibration," Int. J. of Vehicle Noise and Vibration, 5(1-2), pp. 1-35. 
[2] Robinson I., Walsh S., Stimpson G., 1998, "Vehicle accessory tonal noise: experimental determination and subjective assessment,” in: Proceedings of InterNoise 98, Christchurch, pp. 10491052.

[3] Revel G., Santolin C., Tomasini E., 1997, "Laser-Doppler vibration and acoustic intensity measurements for dynamic characterization and noise reduction of a car window lift system," in: Proceedings of $15^{\text {th }}$ International Modal Analysis Conference, Orlando, pp. 1636-1642.

[4] Le Bot A., E. Bou Chakra E., 2010), "Measurement of friction noise versus contact area of rough surfaces weakly loaded," Tribol. Lett., 37 (2), pp. 273-281.

[5] Holm R., "Electric contacts - Theory and application,” Springer-Verlag, Berlin, 1967.

[6] Hallal J., Druesne F., Lanfranchi V., 2013, "Study of electromagnetic forces computation methods for machine vibration estimation," in: Proceedings of VI International Symposium on Electromagnetic Fields in Mechatronics, Electrical and Electronic Engineering, Ohrid, 6 p.

[7] Xut M., Marangoni R., 1994, "Vibration analysis of a motor-flexible coupling-rotor system subject to misalignment and unbalance. Part 1: Theoretical model analysis,” J. Sound Vib., 176(5), pp. 663-679. [8] Xut M., Marangoni R., 1994, "Vibration analysis of a motor-flexible coupling-rotor system subject to misalignment and unbalance. Part 2: Experimental validation,” J. Sound Vib., 176(5), pp. 681-691.

[9] Welbourn D., 1979, "Fundamental Knowledge of Gear Noise - A Survey," in: Proceedings of the Conference on Noise and Vibrations of Engines and Transmissions, Cranfield, Paper C177/79, pp. 914.

[10] Rigaud E., Sabot J., Perret-Liaudet J., 2000, “Comprehensive approach for the vibrational response analysis of a gearbox,” Rev. Eur. Des. Elém. Finis, 1-3, pp. 315-330.

[11] Diop S., Rigaud E., Cornuault P.H., Grandais-Menant E., Bazin B., 2017, “Experimental analysis of the vibroacoustic response of an electric window-lift gear motor generated by the contact between carbon brushes and commutator,” J. Vib. Acoust., 139(6), VIB-16-1524. 
[12] Dupont J.B., Aydoun R., Bouvet P., 2014, "Simulation of the Noise Radiated by an Automotive Electric Motor: Influence of the Motor Defects," SAE International Journal of Alternative Powertrains, 3 (2), pp. 310-320.

[13] Hamzaoui N., Boisson C., Lesueur C., 1998, "Vibroacoustic analysis and identification of defects in rotating machinery, part I, theoretical model,” J. Sound Vib., 216(4), pp. 553-570.

[14] Hamzaoui N., Boisson C., Lesueur C., 1998, "Vibroacoustic analysis and identification of defects in rotating machinery, part II, experimental study,” J. Sound Vib., 216(4), pp. 571-583.

[15] M. Tavakoli, D. Houser, 1986, "Optimum Profile Modifications for the Minimization of Static Transmission Errors of Spur Gears,” J. Mech. Trans. and Automation, 108, (1), pp. 86-94.

[16] Rigaud E., Barday D., 1999, "Modelling and analysis of static transmission error. Effect of wheel body deformation and interactions between adjacent loaded teeth," in: Proceedings of the $4^{\text {th }}$ World Congress on Gearing and Power Transmission, Paris, pp. 1961-1972.

[17] Hiltcher Y., Guingand M., De Vaujany J.P., 2006, "Load sharing of worm gear with a plastic wheel," J. Mech. Des., 129(1), pp. 23-30.

[18] Jbily D., Guingand M., De Vaujany J.P., 2014, “Loaded behaviour of steel/bronze worm gear,” in: Proceedings of the International Gear Conference, Lyon, pp. 32-42.

[19] Carbonelli A., Rigaud E., Perret-Liaudet J., 2016, "Vibro-Acoustic Analysis of Geared SystemsPredicting and Controlling the Whining Noise," in: Fuchs A., Nijman E., Priebsch HH. (eds) Automotive NVH Technology, SpringerBriefs in Applied Sciences and Technology, pp. 63-79.

[20] Reissner E., 1945, "The effect of transverse shear deformation on the bending of elastic plates," J. Appl. Mech., 12, pp. 69-76.

[21] Garambois P., Rigaud E., Perret-Liaudet J., 2017, “NVH robust and genetic optimization of gear macro and microgeometries by using an efficient tooth contact model,” Mech. Mach. Theory, 117, pp. 78-95. 
[22] Perret-Liaudet J., 1996, "An original method for computing the response of a parametrically excited forced system," J. Sound Vib., 196(2), pp. 165-177.

[23] Rigaud E., Sabot J., 1996, "Effect of elasticity of shafts, bearings, casing and couplings on the critical rotational speeds of a gearbox," VDI Berichte, pp. 1230, 833-845.

[24] Fahy F., Gardonio P., "Sound and structural vibration", ${ }^{\text {nd }}$ Edition, Elsevier, Amsterdam, 2007.

[25] Diop S., 2017, "Analyse du comportement vibroacoustique et tribologique d'un motoréducteur de lève-vitre automobile (Analysis of the vibroacoustic and tribological behaviour of an automotive window-lift gearmotor)," (in French), PhD thesis, Ecole Centrale de Lyon, France. 


\section{Figure Captions List}

Fig. 1: Window-lift gear motor. Steel (1) and plastic housings (11) - permanent magnet (2) - carbon brushes (6) - rear (4), center (7) and front bearings (9) - fixation points (12) - coils (3) - commutator (5) - worm (8) - gear wheel (10).

Fig. 2: Radial (a) and tangential (b) magnetic fields $B_{R}$ and $B_{T}$ along the circumference of the air gap (abscissa) for different successive positions of the rotor (ordinate) for the standard operating regime (6500 rpm).

Fig. 3: Time evolution (a) and amplitude spectrum (b) of the input torque $T(t)$ for the standard operating regime $(6500 \mathrm{rpm})$.

Fig. 4: Time evolution and amplitude spectrum of static transmission error STE $\delta(t)(a-b)$ and mesh stiffness fluctuation $k(t)(\mathrm{c}-\mathrm{d})$.

Fig. 5: Spectrograms of the spatial-average mean-square velocity $L_{S V^{2}}(d B)$ in the range $[0-8500 \mathrm{rpm}]$ (a-e). Amplitude spectra of $\left\langle\overline{V^{2}}\right\rangle_{s}$ for the standard operating regime (6500 rpm) (f-j).

(a), (f) - Radial electromagnetic forces (Maxwell pressures) applied to steel stator

(b), (g) - electromagnetic input torque fluctuation

(c), (h) - mechanical imbalance

(d), (i) - static transmission error

(e), (j) - gear wheel eccentricity

Fig. 6: Spectrograms of the dynamic transmitted force $L_{F t}(d B)$ in the range $[0-8500 \mathrm{rpm}]$ (a-e). Amplitude spectra of $F_{t}(\mathrm{~N})$ for the standard operating regime (6500 rpm) (f-j).

(a), (f) - Radial electromagnetic forces (Maxwell pressures) applied to steel stator

(b), (g) - electromagnetic input torque fluctuation

(c), (h) - mechanical imbalance

(d), (i) - static transmission error

(e), (j) - gear wheel eccentricity 
Fig. 7: RMS value of the dynamic response versus operating regime. Excitations considered: normal electromagnetic forces (xx), electromagnetic input torque fluctuation (००), mechanical imbalance ( $\mathbf{\square})$, static transmission error $(++)$, gear wheel eccentricity $(\diamond \diamond)$, overall response $(-)$.

(a) RMS value of spatial-average mean-square velocity $L_{S V^{2}}(d B)$.

(b) RMS value of spatial-average mean-square velocity $L_{S V^{2}}(d B A)$.

(c) RMS value of the dynamic transmitted force $L_{F t}(d B)$.

Fig. 8: Experimental test bench. Gear motor (1) - Reference accelerometer (2) - Flexible mechanical coupling (3) - Powder brake (4) - Torque meter (5) - Speed meter (6).

Fig. 9: Amplitude spectrum of the reference acceleration for the standard operating regime $(6500 \mathrm{rpm})$ (a) and spectrogram during an increasing sweep (0-7000 rpm) (b). 


\section{Figures captions}

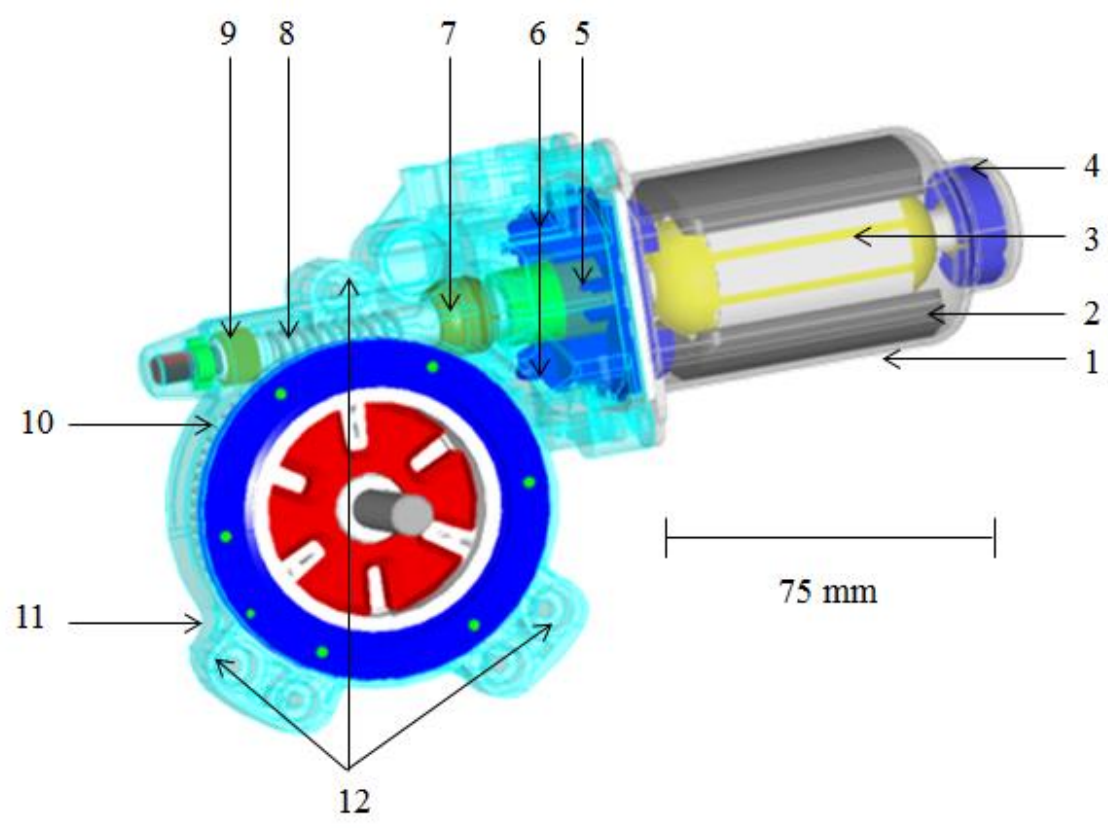

Fig. 1: Window-lift gear motor. Steel (1) and plastic housings (11) - permanent magnet (2) - carbon brushes (6) - rear (4), center (7) and front bearings (9) - fixation points (12) - coils (3) - commutator (5) - worm (8) - gear wheel (10). 

(a)

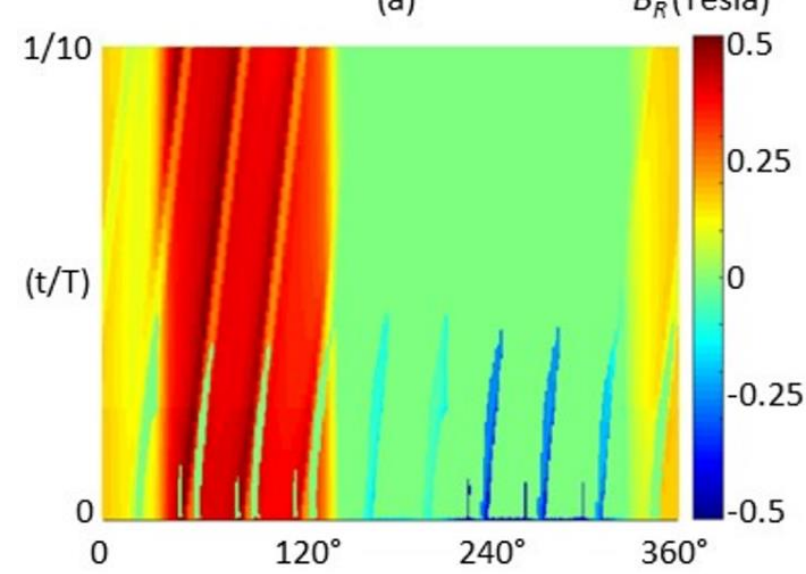

(b)

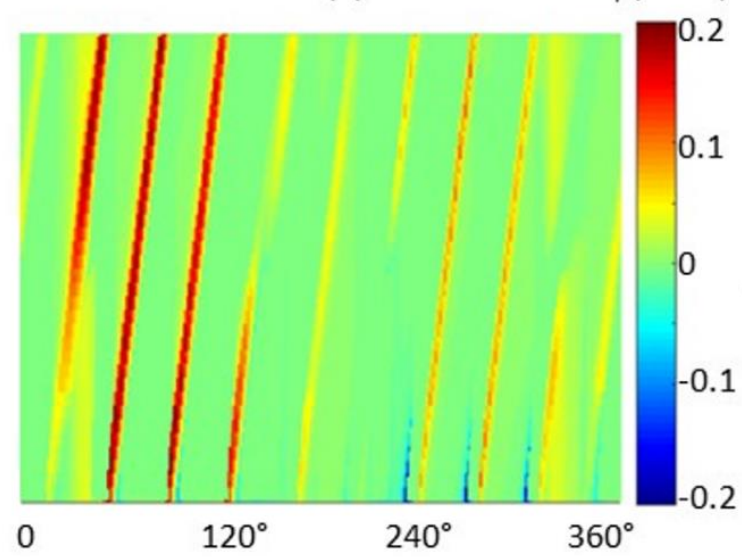

Fig. 2: Radial (a) and tangential (b) magnetic fields $B_{R}$ and $B_{T}$ along the circumference of the air gap (abscissa) for different successive positions of the rotor (ordinate) for the standard operating regime (6500 rpm). 

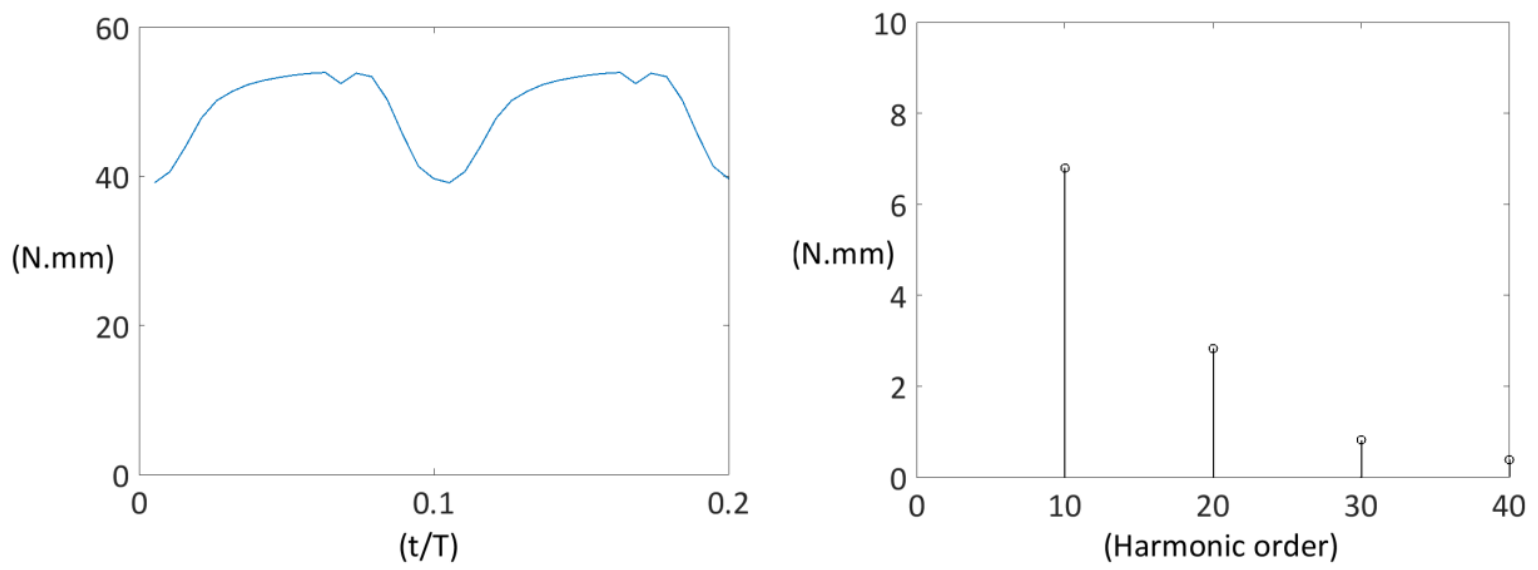

Fig. 3: Time evolution (a) and amplitude spectrum (b) of the input torque $T(t)$ for the standard operating regime $(6500 \mathrm{rpm})$. 

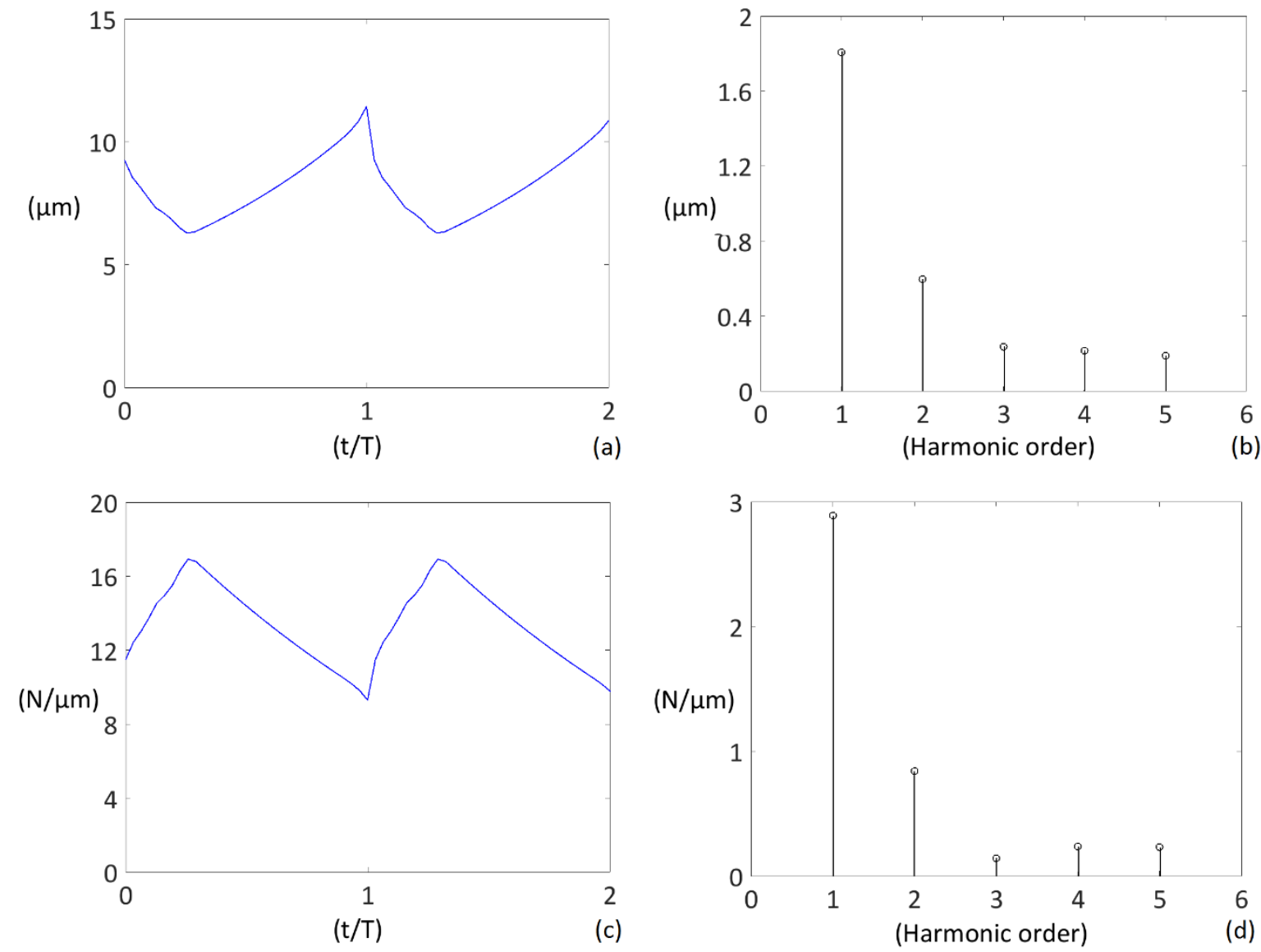

Fig. 4: Time evolution and amplitude spectrum of static transmission error $\delta(t)$ (a-b) and mesh stiffness fluctuation $k(t)(\mathrm{c}-\mathrm{d})$. 

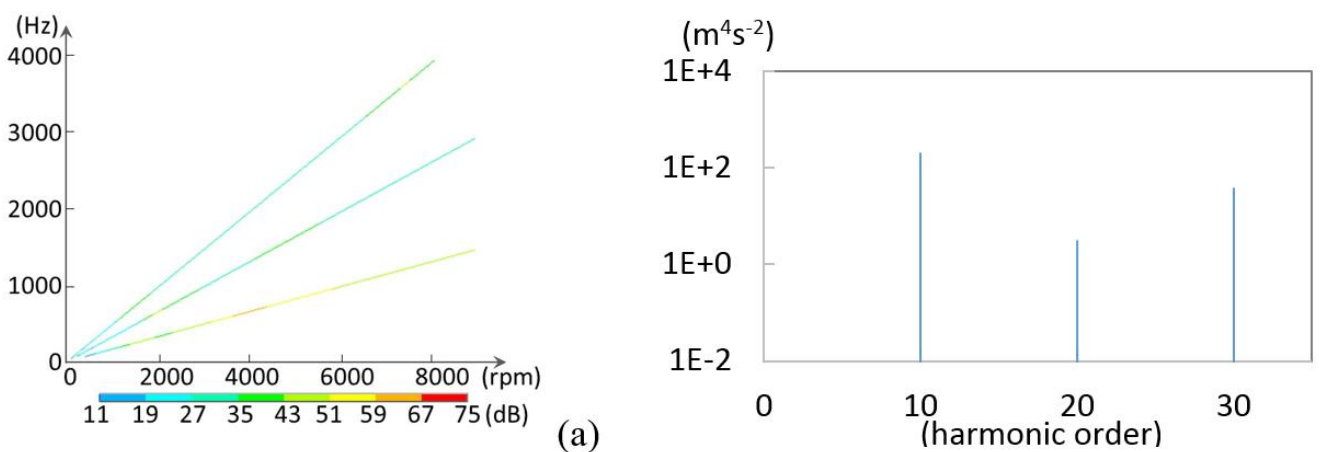

(a)

(f)
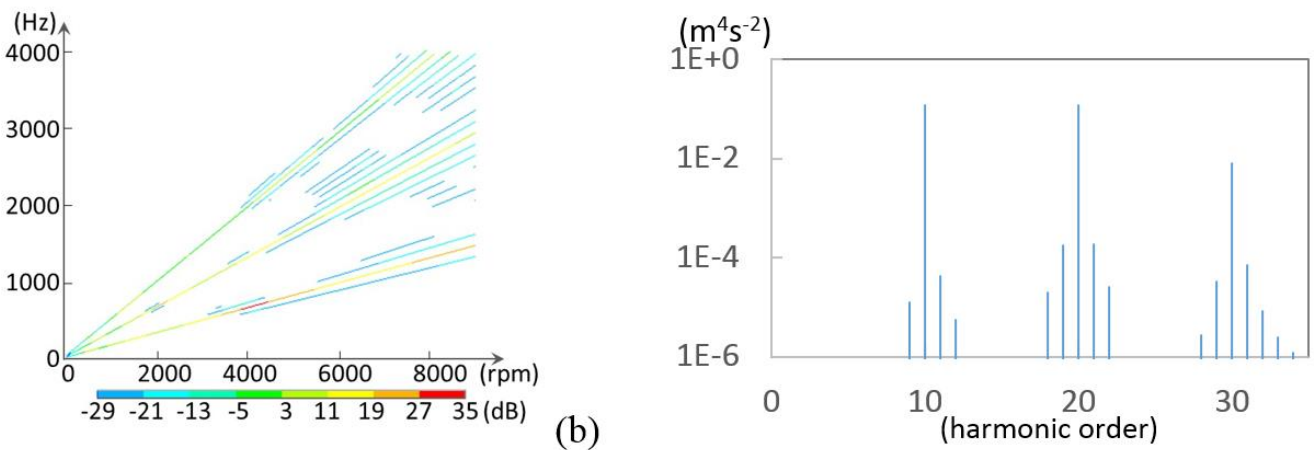

(b)

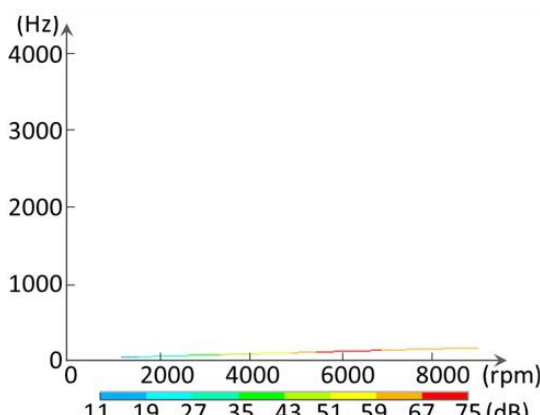

$\left(\mathrm{m}^{4} \mathrm{~s}^{-2}\right)$

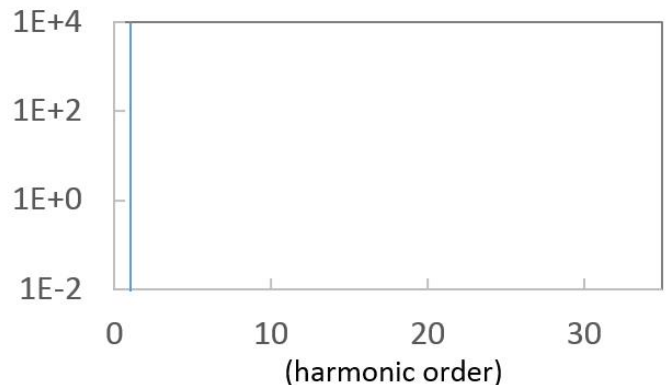

(c)

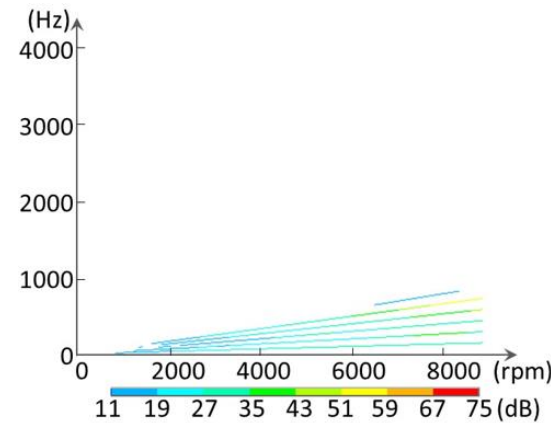

$\left(\mathrm{m}^{4} \mathrm{~s}^{-2}\right)$

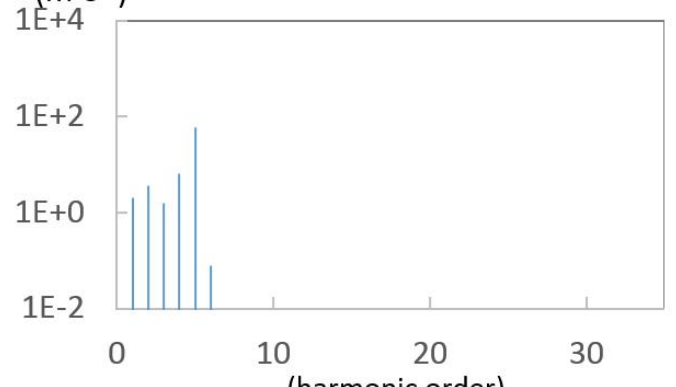

(d)
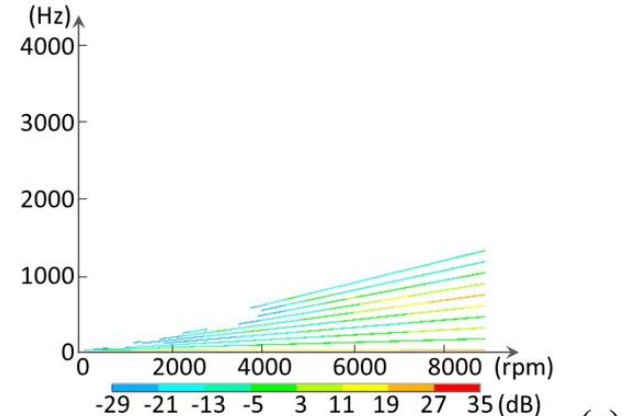

(e)

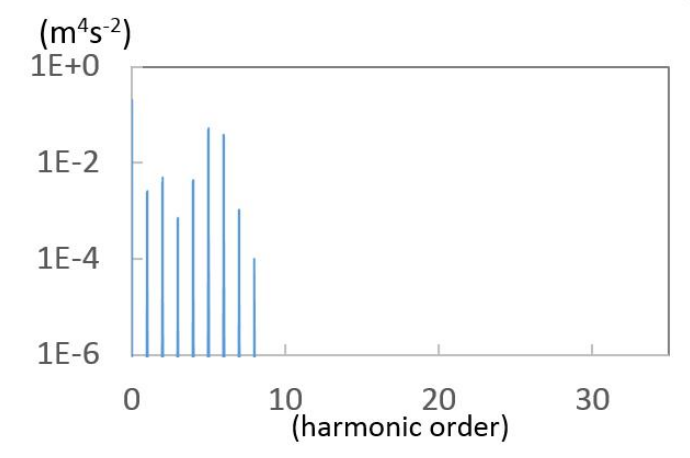

(i)

(g)

(h)

(j) 
Fig. 5: Spectrograms of the spatial-average mean-square velocity $L_{S V^{2}}(d B)$ in the range $[0-8500 \mathrm{rpm}]$ (a-e). Amplitude spectra of $\left\langle\overline{V^{2}}\right\rangle_{s}$ for the standard operating regime (6500 rpm) (f-j).
(a), (f) - Radial electromagnetic forces (Maxwell pressures) applied to steel stator
(b), (g) - electromagnetic input torque fluctuation
(c), (h) - mechanical imbalance
(d), (i) - static transmission error
(e), (j) - gear wheel eccentricity 

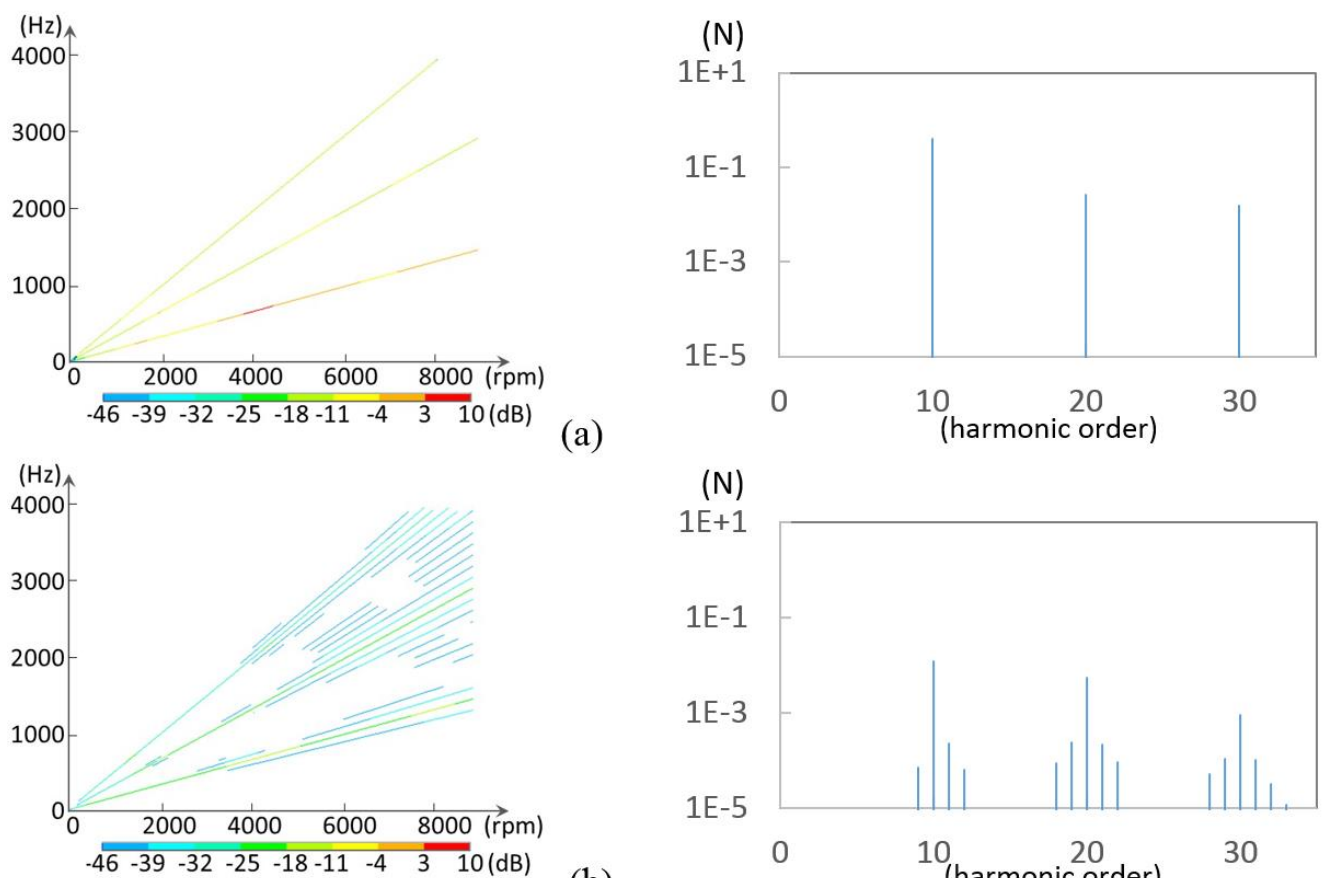

(a)

(N)

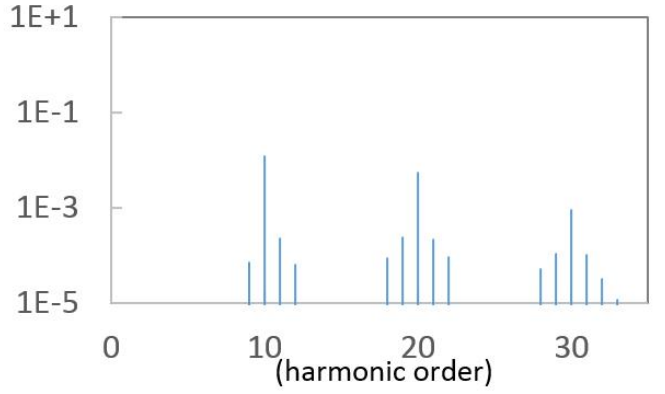

(b)
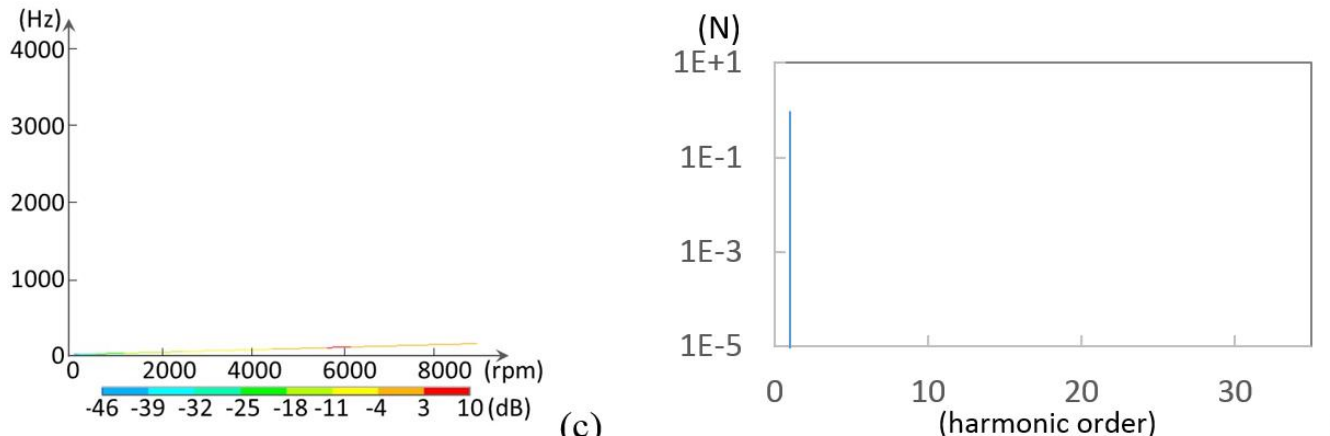

(c)

$$
\text { (N) }
$$
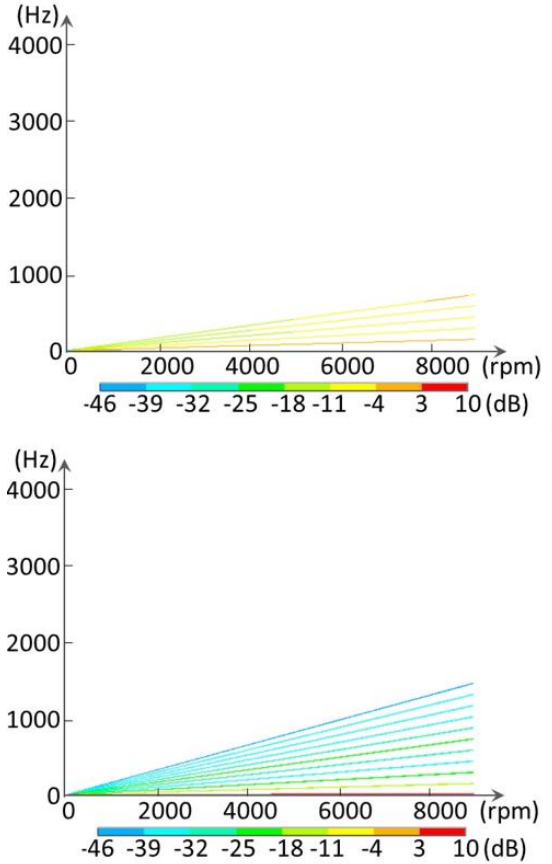

(d)

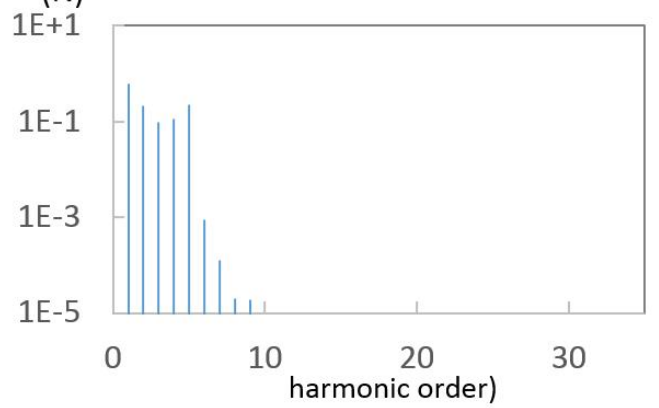

(h)

(N)

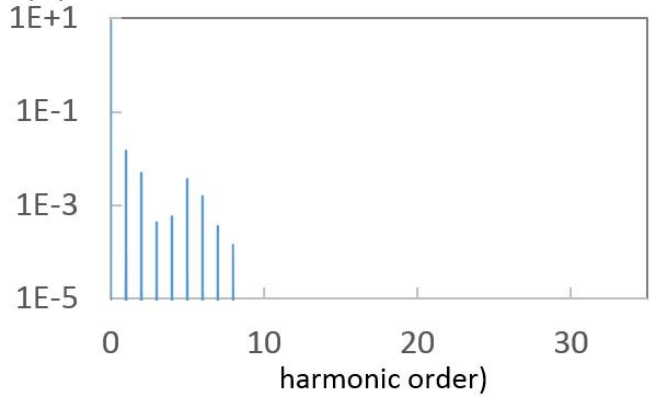

(i)

(e)

harmonic order

(j) 
Fig. 6: Spectrograms of the dynamic transmitted force $L_{F t}(d B)$ in the range $[0-8500 \mathrm{rpm}](\mathrm{a}-\mathrm{e})$. Amplitude spectra of $F_{t}(\mathrm{~N})$ for the standard operating regime $(6500 \mathrm{rpm})(\mathrm{f}-\mathrm{j})$.

(a), (f) - Radial electromagnetic forces (Maxwell pressures) applied to steel stator

(b), (g) - electromagnetic input torque fluctuation

(c), (h) - mechanical imbalance

(d), (i) - static transmission error

(e), (j) - gear wheel eccentricity 


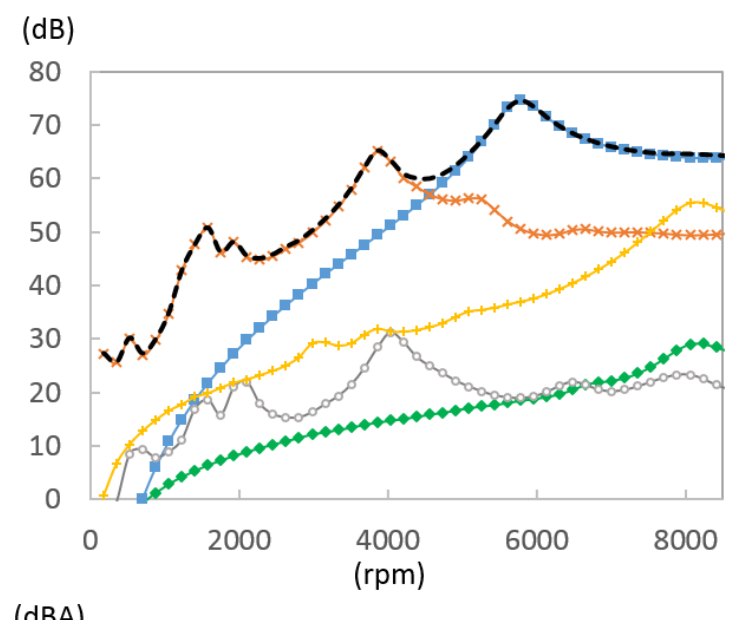

(a)

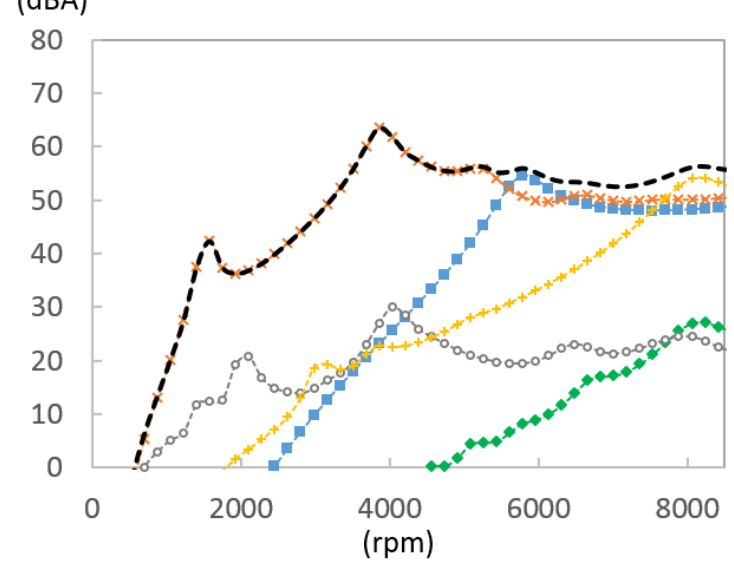

(b)

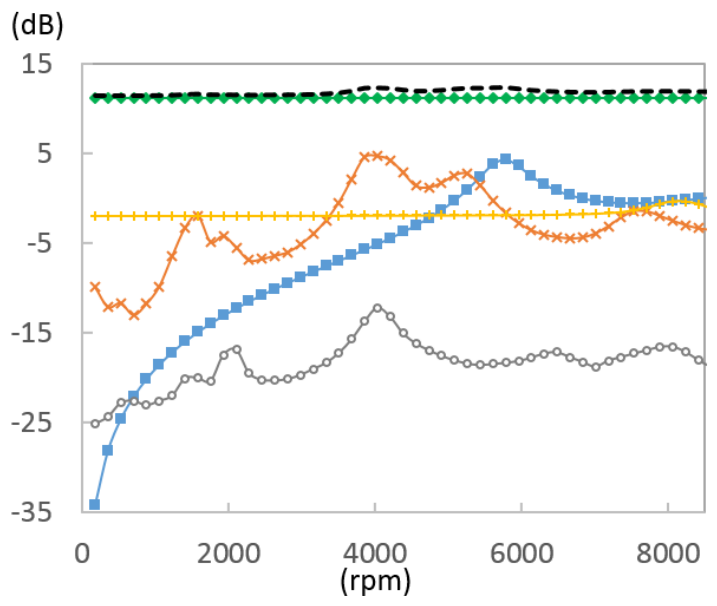

(c)

Fig. 7: RMS value of the dynamic response versus operating regime. Excitations considered: normal electromagnetic forces (xx), electromagnetic input torque fluctuation (००), mechanical imbalance ( $\square$ ш), static transmission error $(++)$, gear wheel eccentricity $(\diamond \diamond)$, overall response $(----)$.

(a) RMS value of spatial-average mean-square velocity $L_{S V^{2}}(d B)$.

(b) RMS value of spatial-average mean-square velocity $L_{S V^{2}}(d B A)$.

(c) RMS value of the dynamic transmitted force $L_{F t}(d B)$. 


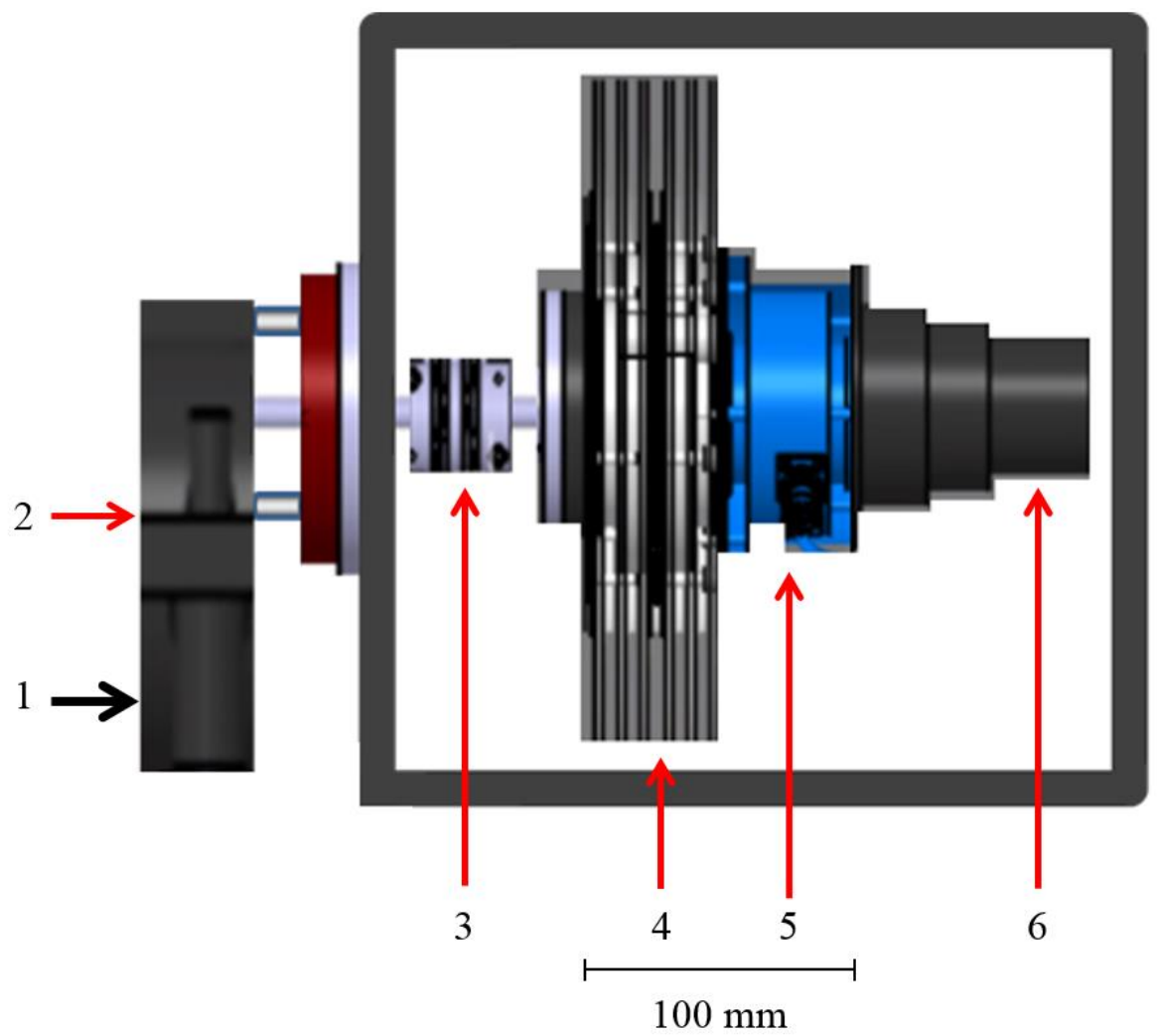

Fig. 8: Experimental test bench. Gear motor (1) - Reference accelerometer (2) - Flexible mechanical coupling (3) - Powder brake (4) - Torque meter (5) - Speed meter (6). 

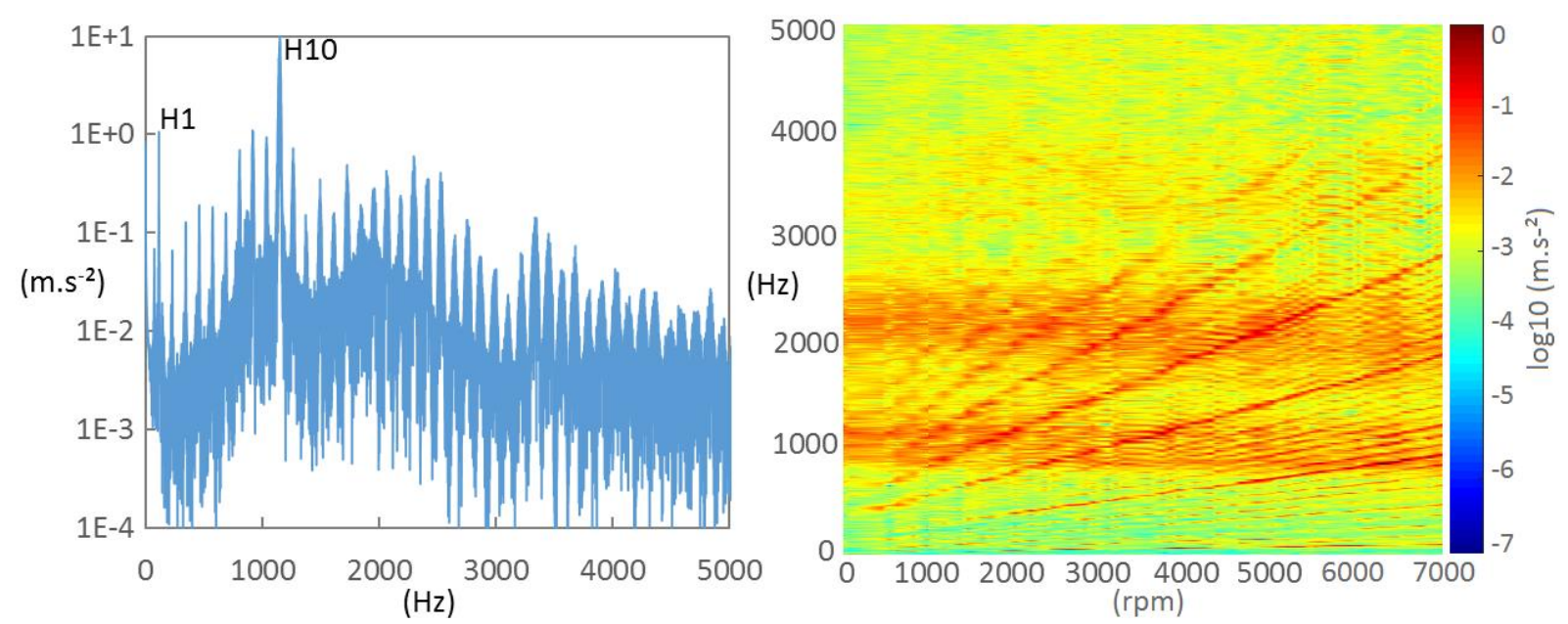

Fig. 9: Amplitude spectrum of the reference acceleration for the standard operating regime $(6500 \mathrm{rpm})$ (a) and spectrogram during an increasing sweep (0-7000 rpm) (b). 